\title{
De las prácticas sociales de referencia a las prácticas en el espacio escénico pedagógico': la construcción del rol docente ${ }^{2}$.
}

\author{
Carolina Merchán Price ${ }^{3}$ \\ Agradecimientos especiales a mis estudiantes \\ de Poéticas. Sin ellos, la acción docente y \\ las indagaciones serían imposibles.
}

\section{Resumen}

Dentro del marco de formación de formadores en artes escénicas surge actualmente la problemática de las relaciones entre los referentes de los formadores, basadas en el teatro como práctica profesional (formación en teatro) y el teatro como herramienta de desarrollo del sujeto (formación a través del teatro). La formación de formadores emerge como el catalizador de tensiones que se generan entre dos visiones institucionales diferentes, donde el punto de encuentro se centra en la tradición de la enseñanza teatral en tanto modelo de la práctica cultural y su transmisión.

En el marco de este trabajo exploramos los elementos de tensión que aparecen en el ámbito de las prácticas pedagógicas de docentes en formación. El dispositivo universitario de formación deviene aquí como un campo de investigación privilegiado para estudiar los procesos de transferencia/transformación de las prácticas de enseñanza de teatro (Aslan, 2005), que además son confrontados con las condiciones y necesidades específicas del público (y del proyecto) escolar (Page, 2006).

Palabras clave:

Enseñanza del teatro, teatro en el aula, formación de formadores.

\section{Resumé}

Dans le cadre du programme de formation de formateurs en arts dramatiques émerge actuellement la problématique des rapports entre les référentiels des formateurs, basés sur le théâtre comme pratique socioprofessionnelle (formation au théâtre) et ceux basés sur le théâtre comme instrument de développement de la personne (formation à travers le théâtre). La formation d'enseignants sert de catalyseur des tensions qui se génèrent entre deux visées institutionnelles différentes, dont les liens se jouent actuellement sur la base des traditions de l'enseignement théâtral en tant que modèle de la pratique culturelle et de sa transmission Dans le cadre de ce travail nous cherchons à explorer les éléments de tension qui émergent dans le cadre des pratiques pédagogiques des enseignants en formation. Le dispositif de universitaire formation devient ici un champ de recherches privilégié pour étudier les processus de transfert/transformation des pratiques d'enseignement théâtrales (Aslan, 2005) lorsqu'elles sont confrontées aux conditions et besoins spécifiques du public (et du projet) scolaire (Page, 2006).

1 Espacio escénico pedagógico corresponde al espacio sugerido donde se desarrollen los procesos propios del teatro como disciplina de formación de sujetos en la escuela. Un espacio escénico privado, extensible e infinito tiene una función específica en la escuela: formar en el conocimiento y en la convivencia; hacer teatro escolar es dotar a los alumnos de un espacio privilegiado para la construcción de su identidad, para el desarrollo de sus capacidades como personas, determinados en aprendizajes específicos: corporales, expresivos, interactivos.

2 Artículo preparado para las Jornadas de estudios científicos JEPEAC, Perpignan 2009 Éprouver, pratiquer, enseigner les arts et la culture. Perpignan, Francia.

3 Profesora del Departamento de Artes Escénicas de la Universidad Pedagógica Nacional cmerchan@pedagogica.edu.co 


\section{El problema: un cambio de mirada sobre la transposición de lo disciplinar específico en la escuela para la formación de docentes}

Uno de los propósitos centrales de nuestros recientes objetos de investigación sobre la construcción de una identidad profesional del docente en teatro al interior de la Licenciatura en Artes Escénicas de nuestra universidad, es el de la redefinición del sentido de la formación en teatro en función de su enseñanza dentro de la escuela.

La dificultad particular que enfrentamos al principio de este proceso parte del hecho de que habitualmente se ha pretendido llevar el teatro a la escuela a partir de un traspaso no didactizado, tanto de los conocimientos y prácticas del teatro profesional, como de las concepciones y prácticas de su transmisión. En esta "aplicación" directa de las prácticas socioculturales se ha dado por sentado que los posibles aprendizajes y sus efectos en el desarrollo de conocimientos, habilidades y competencias se dan per se, sin filtrar las diferencias sustanciales entre el teatro como práctica socio-cultural ${ }^{4}$ y el teatro como medio pedagógico para el desarrollo de los individuos y de los grupos sociales. Aunque justificado históricamente, este traspaso directo de las prácticas del teatro hacia las prácticas escolares con y a través del teatro no tiene en cuenta la modificación fundamental del proyecto de formación y los contrastes en los procesos de transposición didáctica (Chevallard, 1991) que resultan de estas dos opciones: formar profesionales en artes escénicas versus formar profesionales de la docencia teatral.

Este documento presenta algunos hallazgos del ejercicio de reflexión sobre las prácticas docentes al interior del programa, así como del análisis de los dispositivos que amplían la construcción docente en artes escénicas desde el área disciplinar de las Poéticas. En el primer epígrafe, abordaremos algunos

4 Aristóteles. Poética. Ed. Porrúa, México, 1999. Horacio. Ars poética. Biblioteca Nacional, Madrid. Boileau, Arte poético. Ed. Clásica. Anne Ubersfeld, Semiótica del teatro. Ed. Cátedra, 1990. Hauser Arnold. Historia social de la literatura y el arte. Ed. Labor, Barcelona, 1988. Silvio D'Amico. Historia del teatro universal. Editorial Losada, 1954. elementos que explican históricamente la influencia de la tradición profesional teatral y sus prácticas de transmisión en los currículos universitarios de las licenciaturas. En un segundo epígrafe, presentaremos los aportes del dispositivo de formación que permite una práctica reflexiva a partir de la alternancia entre la universidad y el terreno escolar, que se resuelve a través de textos narrativos en los que se evidencian modificaciones, tanto en la concepción del saber teatral, como en las concepciones sobre el rol docente y los procesos de desarrollo de los alumnos. En el tercer epígrafe propondremos el análisis de algunos fragmentos de los textos de los estudiantes, donde se manifiestan las maneras como se resuelven las tensiones. En el cuarto epígrafe presentaremos algunos hallazgos de este análisis, que permiten dilucidar cómo se construye poco a poco la futura identidad profesional de estos estudiantes como docentes de teatro.

\section{Del rol de director al rol docente... sin cambio de vestuario}

Las razones de que esto suceda son múltiples, pero se nombrarán dos específicas, que la experiencia dentro del programa ha definido como centrales, toda vez que se corresponden mutuamente como incidentes en la construcción del rol docente en artes escénicas. La más importante, y de la que se desprende la segunda, es el hecho de que la mayoría de los profesores han adquirido su saber en el área de teatro desde las prácticas sociales de referencia, a saber, el teatro profesional y sus modelos institucionales de transmisión. Son directores, actores, aún críticos o dramaturgos que desempeñan el rol docente al interior de la licenciatura, a partir de los campos y prácticas que han constituido su experticia profesional: en general, trabajan a la manera de directores y/o actores de teatro aún en los entrenamientos de las diferentes disciplinas; como profesionales del teatro, las características de su construcción profesional se focalizan en la excelencia de la producción teatral (y su corolario: el espectáculo) y las dinámicas propias de este campo de prácticas artísticas. Estos procesos de construcción profesional pueden ser comprendi- 
dos y descritos, por ejemplo, a partir de los trabajos de Bourdieu o los más recientes de N. Heinich ${ }^{5}$.

Extensión de esta realidad, es el hecho de que la mayoría de los estudiantes que hacen parte de la carrera entran al programa llevados por la pasión que les despierta el teatro como práctica sociocultural. Quieren aprender a ser actores, directores y/o dramaturgos. Y de ello se desprende también la tendencia de los estudiantes a repetir los esquemas de montaje y dirección profesional de teatro en las aulas escolares, emulando los procesos de creación teatral. Estas dinámicas no siempre son las más adecuadas en ambientes escolares, pero sobre todo hacen difícil analizar y proponer el sentido de las disciplinas que comprende el teatro como herramienta para la educación de los alumnos.

Estas dos constataciones abren el espectro de las indagaciones para comprender los procesos de transposiciones didácticas y pedagógicas, que serían pertinentes desde el quehacer teatral, con el objeto de contribuir a la enseñanza de sujetos en la escuela. En síntesis, las nuevas perspectivas en investigación están actualmente orientadas hacia la definición del objetivo fundamental del programa de Licenciatura en Artes Escénicas como centrado en el desarrollo del niño a partir de los aportes específicos de las artes escénicas como disciplina escolar (Chervel, 1991). Esto supone una reflexión sobre las cualidades de las disciplinas que comprende el teatro como objeto cultural y sobre la manera de movilizarlas como herramientas que aportan al desarrollo de los grupos y sujetos en la escuela.

\section{Un dispositivo de formación basado en la práctica investigativa: el trabajo en el aula universitaria y las extensiones hacia la escuela}

Esta investigación se realiza desde el enfoque descriptivo-interpretativo. Se busca la interpretación y comprensión de los procesos de construcción del conocimiento profesional de los docentes en torno a la práctica y evaluación de los aprendizajes a partir de las experiencias de los propios estudiantes.

5 N. Heinich (2003), La sociología del arte. Madrid: Paidós
El dispositivo procura instrumentar la reflexión a partir de un juego de combinaciones de los diferentes roles que asumen como estudiantes, como docentes noveles y como investigadores de sus propias prácticas.

Se apoya en la perspectiva teórica del interaccionismo simbólico, cuya categoría central es el proceso de construcción de los significados que las personas asignan al mundo que les rodea, a los objetos, a sus acciones y a las demás personas. Una premisa fundamental de esta perspectiva es que "las personas actúan con respecto a las cosas -e inclusive frente a las personas- sobre la base de los significados que unas y otras tienen para ellas; los significados son productos sociales que surgen durante la interacción; los actores sociales asignan significados a situaciones" (Berger \& Lukmann, 2005).

El conocimiento del profesor se estudia con respecto a la reflexión en y sobre la práctica, y desde allí la investigación también tiene como referente de partida la epistemología práctica de Schön (1998) cuando concibe al maestro como un práctico reflexivo. No obstante, este trabajo toma distancia de dicho planteamiento en cuanto a la construcción del conocimiento, ya que en nuestro dispositivo se instrumenta la mirada investigativa a partir de conceptos didácticos que contrastan, tanto con las lógicas de la formación teatral, como con aquellas de las prácticas docentes espontáneas.

Para el análisis de los datos que emergen de las narraciones y textos de los estudiantes, hemos movilizado los conceptos didácticos de:

- Medio didáctico (Brousseau, 1991), que nos permite describir los elementos de saber en juego a partir de la manera como se sitúan en el medio material y simbólico de la actividad. La interpretación de las situaciones de enseñanza-aprendizaje se hace a partir de una lectura dinámica de la actividad resultante de las interacciones entre los elementos del sistema triádico docente-saberalumno.

- Mesogénesis, categoría que nos permite describir la evolución del medio didáctico en tanto terreno material y simbólico en el que se ejercen las acciones de docente y de alumnos. 
- Topogénesis, categoría que nos permite describir aquellos elementos relacionados con los roles y funciones de los sujetos en el medio didáctico, en función de dos dimensiones básicas: las relaciones con el tipo de saber y con el tipo de tarea propuesta.

- Cronogénesis, categoría que nos permite describir los procesos de construcción de los saberes que están efectivamente en juego en las lecciones planeadas o puestas en práctica por los docentes noveles.

En este estudio se articula la práctica reflexiva a los procesos de formación, mediante la investigación narrativa y la discusión con el investigador y los otros sujetos en grupos de discusión, sean el propio docente y sus estudiantes quienes reconstruyan el conocimiento y propongan las directrices hacia la escuela.

La propuesta se ha dirigido a redefinir los contenidos específicos del curso de Poéticas en sexto y séptimo semestre ${ }^{6}$ y su pertinencia para el aula escolar; sistematizar y analizar las prácticas de formación que se realizan al interior del espacio académico universitario en la construcción formativa de los futuros formadores en artes escénicas con respecto a los contenidos que circulan dentro de la comprensión de la historia del teatro, la elección de los temas a profundizar; y los temas que emergen a partir de las conversaciones de los estudiantes con las obras. A su vez, la socialización permanente de las conversaciones y trabajos escritos permitieron ampliar poco a poco el espectro de los temas sobre los cuales la formación también involucra lugares de reconocimiento.

En la dimensión formativa del dispositivo, los instrumentos de interpretación se proponen en dos planos. Por un lado la sistematización y consecuente análisis de las lecturas de exploración de los estudiantes; los niveles de conversación, actualización de las lecturas, la comprensión de los ejercicios en

6 Eric Bentley. The life of drama, 1964. Ed. Paidós. Buenos Aires. Este autor discute las diferencias en la concepción de los términos específicos dramáticos y los referentes en la cotidianidad. donde juega sobre todo un papel fundamental la disposición del estudiante a abrir temas de conversación y debate con sus compañeros desde las obras. Exponen en muchos casos su propia forma de pensar. Por otro lado, la elección de temas que, desde la historia, alimentan la comprensión de ese momento y de la actualidad poniendo sobre la mesa las relaciones entre uno y otro momento histórico, visiones de mundo, comprensión de la propia realidad a partir de poder discutirla.

Esta metodología permite recoger material de análisis sobre los diferentes tópicos de revisión del programa, de la estructura de la clase, de las relaciones que con los contenidos tienen los estudiantes y el profesor, de las transformaciones al interior de las relaciones profesor-estudiantes, estudiantes-saberes, proyecciones del área hacia la escuela.

Para efectos de una ilustración de nuestro análisis, en los fragmentos de ejemplificación indicaremos gráficamente los indicios relativos a fenómenos mesogenéticos: los indicios relativos a los saberes expertos, les indicios relativos a conductas (de comportamiento) expertas y los indicios relativos a la dimensión formal de las tareas; los.indịçiọs los topogenéticos y los indicios, los relativos a fenómenos cronogenéticos.

\section{"Poéticas"7 como espacio académico para la investigación de los aportes del teatro en la formación cultural}

En particular, el área de Poéticas registraba dentro de los objetivos específicos el estudio de la historia del teatro en la historia. En un principio, el interés estuvo enfocado hacia la comprensión de las estructuras dramáticas, modelos de la práctica teatral, cúmulo de información que se consideraba necesaria para un director o un actor culto, aún para un público formado; pero deficiente en el conjunto de saberes para un formador en artes escénicas para la escuela. Este enfoque aparecía como deficiente en tanto no lográbamos discernir el sentido que podía tomar

7 Poéticas es el espacio académico que, con las áreas de Cuerpo, Voz y Actuación, corresponden al Núcleo Integrador de Problemas de lo disciplinar específico teatral dentro de la Licenciatura en Artes Escénicas de la Universidad Pedagógica Nacional de Bogotá. 
esta área en su extensión en la escuela, más allá de la muy vaga definición de contribuir a la "cultura general" de los alumnos. En los ejercicios que, desde la práctica pedagógica situaban los contenidos de la materia, se emplazaban propuestas de aula en las que se limitaba al estudiante a repetir/transmitir información enciclopédica sobre el contexto de creación de alguna obra, conceptos específicos sin mayor contextualización o acaso la lectura en voz alta de la misma. En el siguiente ejemplo (proposición de un proyecto de clase antes de conocer la escuela en la que se realizó la práctica) una estudiante de VI semestre propone la obra Andrómaca de Racine para alumnos de grado 10 (15-16 años). Es un colegio público, de estratos populares, la mayoría de los alumnos nunca han tenido teatro, no han visto teatro, no han ido a teatro. Para su clase le han programado tres sesiones de hora y media, una vez cada semana durante tres semanas:

1. (1)El primer día de clase trabajaremos sobre el término de tragedia,

2. basándonos en la Poética de Aristóteles, enfatizaremos en la Fábula, los

3. Caracteres y en las Peripecias. Hablaremos de ejemplos concretos de

4. personas de la vida cotidiana que nos puedan ayudar a entender lo que

5. significan los caracteres, por ejemplo el señor de la tienda es malgeniado y

6. avaro. El alumno que diga un ejemplo puede representarnos o imitarnos a la

7. persona que está describiendo, su forma de hablar, de pararse, etc. La tarea

8. para los alumnos será leer Andrómaca de Racine, dividirse en grup.os de.6.

9. personas, y.cada grupo escoger un acto para trabajar. Este acto tendrá que

10. ser releído para la clase. (Estudiante 1. Sexto semestre, II-2007).

Como podemos constatarlo en el fragmento escogido, la focalización de los contenidos se hace a partir de una concepción muy clara del rol docente como transmisor de un saber de tipo enciclopédico, organizado alrededor de conceptos o nociones (indicios) que son movilizados a través de tareas escolares básicas (hablar, escribir, leer... indicios), que pueden estar relacionadas en un inicio con prácticas socioprofesionales, como el trabajo de mesa ${ }^{8}$.

En la séptima línea hemos subrayado aquellos indicios que corresponderían potencialmente al proyecto escolar de fomentar aprendizajes a partir de lo disciplinar específico (subrayado los indicios): aparece la intención de introducir una mirada sobre los comportamientos cotidianos vs. los extracotidianos, en tanto saber específico trabajado en la licenciatura a partir de los textos de Grotowsky (2000). Sin embargo, no aparecen indicios claros de una articulación entre las tareas escolares propuestas y este proyecto de transformación de los comportamientos cotidianos a partir de aquellos que se trabajan en el texto de Racine. La relación con estas prácticas no parece hacer parte de un proyecto consciente del docente, quien las considera como algo que debería surgir, casi de manera espontánea, a través de la imitación (línea 7), a través de las actividades escolares que hemos subrayado con doble línea.

En los casos en que se intentaba ampliar la lectura en voz alta a lectura dramática (con entonación de voz, construcción mínima de los personajes, inserción de algunos juegos escénicos), la articulación no didactizada, es decir, no pensada en función del proyecto de transformación del sujeto mediante el trabajo en teatro, resultaba en lecturas planas. El gesto profesional docente que surgía, entonces, era el de enviar a los alumnos con recomendaciones de entrenamiento en casa, tomando como referente el entrenamiento del actor.

En muchos casos, los estudiantes iniciaban su clase definiendo el tema desde la organización de un "texto del saber", definido desde las prácticas universitarias de los estudios literarios en el área (cultura general) y, paso seguido, entraban sin articulación ni relación explícita en juegos escénicos en el aula (Buysse, 2007):

8 Trabajo de mesa: constituye una de las etapas importantes de un montaje teatral. Es, en especial, el momento en que actores y director se encuentran alrededor de una actividad de lectura que constituirá la base del trabajo actoral y del montaje mismo, en tanto que interpretación y actualización del texto. 
1. (2)Inicialmente haremos con los alumnos un círcule en el espacio y dạrẹ́ la

2. indicación de que miremos a cada uno de los compañeros con los que

3. empezaremos el trabajo que miremes sus ojos, su nariz, sus piernas, sus

4. manos, todo su cuerpo. Esto para crear un contacto con los compañeros, que

5. el alummo ẹntrẹ en un trabajo con el otrọ y entienda que ahora hace parte

6. fundamental de un grupo, y todo lo que pase cọn él afectará al resto de

7. compañeros. (Propuesta de la segunda clase de tres, primera parte de la

8. sesión. El resto está planeado del mismo modo. $)^{9}$

La estudiante desea proponer de entrada un ejercicio de reconocimiento del otro (líneas 14 ). No hace referencia a la tarea que ha dejado la clase anterior de leer Andrómaca. Tarea que se queda en el limbo como ejercicio intelectual. Un ejercicio de inicio de taller como el que plantea depende de una disposición de parte de los alumnos para llevar su cuerpo a la clase, y hacerlo parte del "saber", del medio a través del cual van a aprender algo. En este caso, a hacer parte de un grupo (líneas 5 y 6 ). Podemos constatar que el referente de la docente novel es el de las prácticas y los saberes típicos de un grupo de teatro.

Las dinámicas profesionales, propias al funcionamiento del actor en un grupo de teatro, orientan claramente esta actividad propuesta, sin que logre la estudiante plantear las relaciones necesarias entre el proyecto inicialmente develado a los alumnos (leer y actuar fragmentos de Andrómaca) y las prácticas habituales del funcionamiento profesional.

La estudiante termina por proponer unas intervenciones de enseñanza que resultan de un patchwork que retoma de su propia experiencia de aprendizaje de los talleres de cuerpo o de actuación al inicio de la carrera de Licenciatura. La docente novel asume su rol como si fuera directora de teatro

9 Estudiante 1, II-2007. y toma a los alumnos de una clase de grado décimo como si fueran alumnos que han elegido teatro en una vocacional, o bien como si todos fueran candidatos a actores. No re-contextualiza sus propuestas desde las limitaciones de espacio, tiempo, y público escolar. Paradójicamente, podemos observar en el proyecto saberes que podrían ser considerados legítimos desde esta área, y que son movilizados en otras disciplinas como la educación física y corporal: la consciencia del cuerpo en un colectivo de cuerpos, la colaboración u oposición de los cuerpos en un trabajo de grupo, la capacidad de descentrarse como individuo y desarrollar acciones que tengan en cuenta la dimensión colectiva de la actividad (como por ejemplo, en los juegos y deportes colectivos), etc. El medio didáctico (indicios) aparece aquí habitado de un enorme número de objetos de saber potencialmente significativos, pero que no están relacionados explícitamente entre sí por el proyecto docente.

Éstas y otras peripecias nos llevaron a revisar los programas del área: ciertamente las clases tipo cátedra, centrar el problema de análisis en las estructuras dramáticas y el contexto histórico; durante 10 semestres no parecían dar a entender mayores alternativas de acción con las obras en el espacio escolar. Ciertamente, este tipo de acercamiento a las obras no instrumentaba a los estudiantes para un trabajo en el aula de clase. Por tanto, fue necesario ampliar el marco de discusión de los textos tanto teóricos como artísticos (obras escritas a través de la historia), procesos creativos que se desprenden del conocimiento de los modelos, etc., en aras de dilucidar las mediaciones posibles que de ellas emergen.

Dos elementos nos han permitido acompañar a los estudiantes en el manejo de este paulatino proceso de ajuste entre el proyecto escolar y los aportes de la formación. El primer elemento es, sin duda alguna, la confrontación a la realidad de las prácticas escolares, en las que emergen de manera evidente las tensiones entre los dos tipos de proyecto (educación en teatro vs. educación a través del teatro). El segundo elemento es ofrecer momentos que, dentro de los espacios universitarios de la formación, permitan a 
los estudiantes trabajar estas tensiones que se generan, básicamente a partir de procesos de escritura reflexiva (Vanhulle, en imprenta).

Una estudiante escribe la siguiente reflexión después de tres sesiones de práctica en un colegio privado. La ponemos en evidencia porque en ella -y después de muy poco tiempo de práctica- se da cuenta de la importancia de tener en cuenta las respuestas de los alumnos a la hora de elegir una obra y definir los procesos:

1. (3) Desarrollando el trabajo nọtẹ una dificultad que se presentaba con dos

2. caras: o.ṇo supịmọs llevạr un texto clásico como El médico a palos de Molière

3. para un grupo de jóvenes en plena edad de rebeliones y de conflictos

4. internos, no es lo más pertinente... sabiendo que yọ al leẹr el texțo lo dișf̣rutẹ́,.

5. ṃẹ dẹlẹitẹ́ con el lenguaje. Pero çọnșiḍẹro.que tal vez ellọs țiẹnẹn rạzón:n: la

6. comedia, según lo visto en cuarto semestre de poéticas, es donde el ser

7. humano confronta valores sociales ofamiliares, para luego sobrevenir el

8. perdón y la reconciliación; lo que la hace, crẹo. yo̊ para jọvenenẹs dẹ dịeçisẹ́iş y.

9. dịẹciṣiette.(añọs) poco interesante... Es más, en el grupo de teatro al cual

10. pertenecen algunos estudiantes, están trabajando autores como Samuel

11. Beckett. Sí, de Molière a Beckett hay un gran espacio.

En este fragmento podemos notar el énfasis en el tema "escuchar a los alumnos". La impresión de fracaso en su práctica lleva a la estudiante/docente a un nuevo emplazamiento topogenético (Sensevy, 2007). Es decir, a una reflexión y reconfiguración de las posturas y funciones dentro de la terna didáctica docente-saber-alumno. Hemos subrayado lọs indịiçiọ que nos permiten identificar este proceso de cuestionamiento sobre los roles respectivos del docente y de los alumnos en función de la pertinencia de los contenidos (indicios).
La reflexión de la estudiante pone en evidencia que Poéticas no podía seguir siendo un espacio puramente informativo sobre la historia del teatro en la historia, sin tener en cuenta un tercer invitado que transforma el contenido de la clase, y de paso otorga un nuevo sentido a la carrera también desde esta área: el alumno en la escuela. El tercer invitado, que hará parte del proyecto de enseñanza, es el alumno en tanto en cuanto sujeto de la escuela como institución. Este "nuevo" elemento conduce a la transformación de la concepción sobre el perfil docente en artes dramáticas: este no es un futuro actor, no es un receptor de datos e información inmutable; es un futuro formador en artes escénicas, y por lo tanto conocer de él, él de sí, y sus opciones de construcción docente, es parte del contrato didáctico de formación. En las líneas 4 y 5 de nuestro fragmento vemos, en la relación planteada entre el "yo" narrador y los alumnos, indicios de reflexión hacia la construcción de un rol profesional específicamente ligado a cuestionamientos docentes que se organizan en dos categorías:

- Topogenéticas: aquí, las reflexiones ligadas a las condiciones de la situación para que la actividad tenga sentido en un grupo con características específicas ("los jóvenes de 16-17 años en plena edad de rebeliones y de conflictos internos");

- Mesogenéticas: en el fragmento se manifiestan igualmente elementos potenciales de reflexión en términos de "medio didáctico" para la acción: en efecto, la reflexión topogénica no se hace aquí con referencia a los aspectos relacionales docente-alumno, sino a partir de una reflexión alumno-objeto cultural. Aunque de carácter hiperbólico, la afirmación "sí, de Molière a Beckett hay un gran espacio" (línea 11) contiene ya el germen de una reflexión que podría desembocar en planificaciones que tengan en cuenta la zona proximal de desarrollo (Vygotski, 1931-2000).

\section{Discusión: la necesidad de involucrar la noción de desarrollo escolar en el espacio académico universitario}

Chevallard (1991) dice que los saberes se gastan en su funcionalidad. Aportaríamos que pierden 
funcionalidad si en el cambio de contexto no se lee la necesidad de transformaciones en el medio didáctico de la formación para el medio didáctico de la enseñanza. Lo que mostraremos a partir de unos breves análisis de nuestro dispositivo de formación universidad-terreno escolar, es cómo si en un inicio los estudiantes tenían tendencia a empobrecer la funcionalidad de los saberes en el paso de su propia formación a la enseñanza en la escuela, la toma de consciencia de la especificidad del terreno y del proyecto escolar tiende a favorecer ahora procesos de boundary crossing (Engeström, R. y Kärkkäinen, M. 1995), es decir que los estudiantes tienden ahora a lograr transferencias de saberes de un contexto a otro, readaptándolos a las características del nuevo contexto y reconfigurándolos en función de una transformación del proyecto de formación: de una formación esencialmente centrada en teatro hacia una formación a partir del teatro.

Es decir, el objeto de saber no es el mismo hoy que hace cinco años, cuando comenzaron las prácticas pedagógicas al interior del programa. De hecho, aunque parece el mismo objeto no lo es, pues igual tipo de contenidos proponen un espectro de intervención distinto si es para un actor, que si es para un docente. Lo que quiere decir que, desde hace tres años, se iniciaron ciertos cambios de diversos tipos para que hubiera correspondencia entre la acción docente al interior del programa y las propuestas de los estudiantes en sus prácticas pedagógicas en la escuela.

Juicios como "los estudiantes no saben planear una clase", "no entienden cómo dar una clase", "no tienen en cuenta el contexto escolar", eran frecuentes entre los profesores. Algo faltaba, y comprender los asuntos relativos a los vacíos de sentido que no permitían avanzar en el camino de construcción de los futuros formadores llega hasta estos hallazgos que hoy presentamos. En las encrucijadas emergen algunas preguntas que van viabilizando nuevas transposiciones que darán luces a la configuración de la licenciatura. ¿Por qué enseñamos Poéticas en la universidad como si fuera una escuela de formación de actores? (al igual que otras disciplinas teatrales como Cuerpo, Voz, Actuación, así como una Pedagogía en el limbo teórico, muchas veces sin referentes prácticos concretos). ¿Cómo debe ser el área de Poéticas si la carrera es una licenciatura en Artes Escénicas? ¿Cuáles han de ser sus contenidos, sus procesos de enseñanza/aprendizaje, sus objetivos? ¿Cómo se transforma el objeto si se articula la noción de escuela al programa del área? y, la que nos pareció más importante para empezar a ampliar los espectros conceptuales del área: ¿̇ómo son, qué piensan, qué intereses tienen los estudiantes en tanto estudiantes de licenciatura? De hecho, lo indagado nos muestra hoy que fuimos desestimando la importancia de haber construido una escuela de formación de actores, a tal punto que dimos por sentado que el perfil de los estudiantes era uno, y no se tuvo en cuenta quiénes eran realmente, qué intereses tenían, más allá de si eran buenos o malos actores, con potencial o no, porque de eso sí sabíamos. Difícil.

Es así como en I-2008 iniciamos, de manera más formal, prácticas pedagógicas formativas con el acompañamiento del área de Pedagogía. Estas prácticas tienen una duración de tres horas en el colegio cada 15 días; tienen como objetivo principal acercar empíricamente no sólo la noción de niños, sino los mundos de la escuela, a nuestros mundos de la licenciatura. En ese momento aparecen dentro de la clase preparatoria de los proyectos de aula, al inicio de la experiencia, reflexiones como la que citamos a continuación (subrayamos el hecho de que esta estudiante está ya en sexto semestre). La primera parte de su trabajo es un largo listado de contenidos de las áreas de Voz, Cuerpo, Actuación y Poéticas (fragmento de ejemplo más adelante):

1. (4) hasta inicios de este semestre, fue cuando me di.çuențta de que toda esta

2. información y conocimientos se me impartían no para constituirme en una

3. buena o mala actriz, sino en una dọcențte, y en ese sentido, todos estos

4. conocimientos no sólo traspasaban mịivịda, sino que ahora debían

5. constituirse como la herramienta que ạtrayẹșạríą la vidụạ de ototrọ ${ }^{10}$.

10 Estudiante 2. I-2008. 
Estas palabras iniciales de reflexión, después de conocer el colegio donde harían su práctica, corroboran un mismo tipo de desplazamiento topogénico -como el anotado en nuestro segundo fragmento-, esta vez con una reflexión sobre la necesidad de cambiar el perfil del estudiante en este tipo de formación: de futuro actor a futuro docente. Sitúan igualmente el tiempo necesario para entender (indicios cronogéneticos) como un elemento para tener en cuenta dentro del análisis. Seis semestres después de iniciar su carrera de licenciatura, ella se da cuenta -porque va al lugar de la práctica- que está estudiando para una licenciatura (indịicịọs). Se da cuenta de que los saberes que recibía en la formación, y que ella consideraba construían su rol como actriz, son para ser pensados como herramienta para enseñar a otro (líneas 4 y 5). Haber integrado el espacio escuela a través de las prácticas dentro del programa del curso de poéticas, muestra la intención concreta de la institución universitaria-profesor de enriquecer los medios didácticos para producir nuevos tipos de transposición más adaptados a las necesidades del público escolar. En clase, este enriquecimiento pasa por la instauración de los espacios ligados a una actividad investigativa de los estudiantes; en el terreno escolar, pasa por los procesos generadores de tensiones que implican adaptaciones de las concepciones profesionales de los estudiantes y un nuevo estatuto para los saberes trabajados en la universidad: notemos que en la reflexión de este último fragmento, el desplazamiento topogenético de la estudiante está ligado a una transformación del estatuto de los saberes trabajados en el espacio académico como "herramienta para la construcción del otro".

\section{La construcción del perfil profesional del estudiante}

\section{El espacio académico: un lugar para la confrontación}

El siguiente cuadro define las diferencias que hemos ido estableciendo, desde entonces, entre el área de Poéticas en el espacio universitario (antes de pensarlo hacia la escuela en acciones concretas), y aquello que se propone como articulación hacia la práctica docente en la escuela. Es el punto de partida para ser construido con los estudiantes en clase, en tanto es con ellos que va tomando forma discernir del objeto sus posibles dimensiones pedagógicas. En los ejercicios que vamos a analizar tomamos solamente algunas de las dimensiones contenidas en el cuadro, desde una de sus posibles acepciones (marcadas con ${ }^{\star}$ ).

\begin{tabular}{|c|c|}
\hline Universidad/Licenciatura & Escuela \\
\hline $\begin{array}{l}\text { La historia del teatro en la historia. } \\
\text { Lecturas y saberes formales y temáticos. } \\
\text { Hitos. } \\
\text { Autores dramáticos. } \\
\text { Relación entre la realidad y las obras. } \\
\text { * Qué se necesita para que haya re-actualización. }\end{array}$ & $\begin{array}{l}\text { *Dimensión temática: el teatro como forma que cristaliza el conocimiento de } \\
\text { las acciones y prácticas humanas (en lo social y en lo individual): poner al alcance } \\
\text { de los niños otras experiencias de vida relativas a espacios humanos, relaciones } \\
\text { sociales, acciones e interacciones (representaciones, valores, conflictos, tipos de } \\
\text { acciones y de comportamientos). } \\
\text { Dimensión de conocimiento cultural: instauración de ejes y referencias históri- } \\
\text { cas de la construcción de la cultura (o las culturas) con respecto al presente. }\end{array}$ \\
\hline $\begin{array}{l}\text { Comprensión de lectura (niveles). } \\
\text { *Estructuras dramáticas. } \\
\text { Producciones escritas a partir de las prácticas so- } \\
\text { ciales de referencia (ensayos de análisis, motivos, } \\
\text { categorías, puesta en escena, crítica): } \\
\text { - Producción literaria paralela (creación) } \\
\text { - Ensayo crítico } \\
\text { - Comentario }\end{array}$ & $\begin{array}{l}\text { Dimensión discursiva y semiótica: } \\
\text { A. Conocimiento del género dramático y de sus características discursivas y tex- } \\
\text { tuales. } \\
\text { *Puesta en práctica de otros géneros literarios constitutivos de las prácticas socia- } \\
\text { les de referencia, en especial, aquellas relativas a la experticia cultural del público } \\
\text { receptor. }\end{array}$ \\
\hline $\begin{array}{l}\text { Producción oral a partir de las lecturas: } \\
\text {-Lecturas dramáticas (voz, tono, silencios, acota- } \\
\text { ciones, estados de ánimo, conflictos). } \\
\text {-Recepción oral (sentido y cualidades formales). }\end{array}$ & $\begin{array}{l}\text { Dimensión discursiva y semiótica: } \\
\text { B. Conocimiento y práctica de la oralidad, de sus características discursivas, tex- } \\
\text { tuales e interactivas. }\end{array}$ \\
\hline $\begin{array}{l}\text { - Análisis de la forma de los escritos dramáticos: } \\
\text { - Lo dialógico y el diálogo. } \\
\text { - La acotaciones e indicaciones escénicas. } \\
\text { Dimensión "performativa" del hecho dramático a } \\
\text { partir del teatro. }\end{array}$ & $\begin{array}{l}\text { Dimensión artística y estética: } \\
\text { - Codificaciones de la acción humana. } \\
\text {-Apropiación y modificación de las codificaciones culturales (adaptación a las con- } \\
\text { cepciones y valores del grupo, del individuo). } \\
\text {-El trabajo del lector: análisis de los mecanismos re-creativos de la lectura. }\end{array}$ \\
\hline
\end{tabular}


Con respecto a los ejes que se distinguen en la Universidad, los estudiantes comprenden en particular los contextos de reproducción de las obras,

1. (4) Área de poéticas, estudio de la Tragedia griega, de la Comedia, del teatro

2. de la Edad Media, análisis de Shakespeare, Siglo de oro, teatro francés,

3. romanticismo alemán. Para algunos momentos de la historia del teatro y su

4. relación con la historia de la humanidad. Así mismo reconocẹr conceptos X

5. pautas de análisis de las obras ${ }^{11}$.

Las relaciones entre historia y modos de representación (indicio) distinguen procesos específicos a determinar al interior de las obras. En general, el nivel de lectura comprensiva y apropiación desde las acotaciones en los textos dramáticos hacia la representación es alto, toda vez que las destrezas que adquieren hacia la actuación apoyan a profundidad la asimilación de textos y situaciones dramáticas.

Más adelante en sus reflexiones, la misma estudiante hace una disquisición comparativa en relación a cómo se ve a sí misma en su cercano rol de practicante/docente mientras describe lo que ella considera, en ese momento del proceso, las "no disposiciones" de los alumnos...

1. (5)Por otra parte, se halla lo referente a mi propią vivencia a miformación

2. la confrontación con la realidad del otrọ. En eștọs mụụchacḥọs no existe el

3. rigor de la ropa neutra de trabajo, ni siquiera usaban ropa especial de trabajo,

4. no existe un rigor en cuanto a la disposición para la clase, menos existe un

5. rigor en cuanto al tiempo de clase, es decir, la hora de entrada. El quid del

6. asunto no.son.los mụch hạ̧họọs, es este tipo de formación que nos inculca una

7. serie de parámetros y de normatividades que no son coherentes con la

8. realidad de la escuela ${ }^{12}$.

11 Estudiante 3, VI semestre. Abril de 2008.

12 Idem.
En este párrafo hallamos dos temas que nos dicen del programa que: a. La primera parte sobre la sorpresa que le causa a la estudiante el hecho de que es posible que los alumnos del colegio no hagan caso a la "obligatoriedad" de llevar ropa de trabajo para lo que llaman entrenamiento (indicio). Tiene que ver con las disposiciones del estudiante de la licenciatura y es un comportamiento típico de la formación y de las prácticas de referencia que ellos han integrado; aparece como un saber implícito que los estudiantes en prácticas rara vez piensan en explicitar y en darle sentido; así, la convicción de la estudiante de cumplir rigurosamente en su propia formación con esta norma entra en tensión con el sinsentido que ésta tiene para los alumnos en el colegio (línea 3). b. La molestia que le produce la disposición - muy laxa, por cierto- de los alumnos del colegio ante los horarios, las normas. Llama la atención el reclamo al dispositivo de formación, por la no coherencia entre las normas de este colegio, de corte muy libre, y aquellas que rigen su propia formación universitaria (discontinuo negro).

La estudiante 3 inicia, pues, un proceso de reflexión sobre la coherencia de los topos en los que, dependiendo el lugar que ocupa, permite confrontarse al espacio en el que se forma. Pone como objeto de crítica su propio medio de formación (línẹąs.2 y 6).

\section{Evidencias sobre los procesos de transposición de los saberes teatrales}

En otro de los procesos paralelos de nuestro dispositivo de formación, los estudiantes deben conversar con las obras de teatro. Inician consigo mismos -como individuos y en el colectivo- ante el grupo, la instalación de sus propias maneras de pensar, objetos de pensamiento y capacidad de discusión sobre los temas que emergen en el ejercicio. Estos parten de la intención que se fija en los contenidos de la casilla "universidad" (tabla No. 1), de lo que son los procesos de actualización de las obras, objetos culturales que son la base de nuestra formación. Y tienen como referente específico aquella dimensión que en la casilla de enfrente considera la obra de teatro desde su Dimensión temática: poner al alcan- 
ce de los niños otras experiencias de vida relativas a espacios humanos, relaciones sociales, acciones $e$ interacciones (representaciones, valores, conflictos, tipos de acciones y de comportamientos).

Esta fase de cambios puso al alcance de los estudiantes otras experiencias para confrontar las propias. Un ejercicio más bien difícil de instalar. El primer semestre del ejercicio (II-2007) creó largas discusiones sobre la pertinencia de llevar un registro de las formas propias de pensar. Apareció en las discusiones del aula la pertinencia o no de decir sobre cómo y qué se piensa al leer. Emergieron temores con respecto a confrontar niveles de elaboración sobre un vasto mundo de temas posibles de abstraer. Creó resistencias que tomaron tiempo en ir desapareciendo y que se concretaron en muchas excusas para no presentar trabajos escritos. Puso en evidencia los esfuerzos, probablemente fallidos, de incluir en las diferentes áreas el tema pedagógico como referente sin concreciones claras, que más que dar camino para indagaciones, saturó los discursos todavía sin construir.

Sin embargo, valorando dichos intentos con respecto a los avances -casi dos años después- estos dan pistas sobre la responsabilidad en los docentes al proponer las ampliaciones conceptuales y la importancia de los trabajos conjuntos, que potencie en los estudiantes procesos de boundery crossing y aporte herramientas para el manejo de la policontextualidad inherente a la disciplina teatral y de las características propias de esta formación (Engeström, R. y Kärkkäinen, M. 1995).

El siguiente semestre, el grupo fue más receptivo y el profesor logró ajustar ciertos dispositivos con respecto a prácticas en terreno, que apoyaban las transformaciones en los objetivos de la clase y en los objetos de enseñanza (muchas veces, esfuerzos muy interesantes se pierden por falta de una administración adecuada en desplazamientos y acompañamiento). Las conversaciones con los libros comenzaron a dar resultados edificantes que ponían en el aula temas de discusión. Estudiante 4 elige, a partir de la lectura de Casa de Muñecas, Hedda Gabler (Ibsen) y La más Fuerte (Strinberg) el tema de la noción de mujer a finales del siglo XIX. Con algunos apuntes, confronta a sus compañeros sobre cuánto han pensado o no respecto a lo que significa ser mujer. Las contradicciones entre Hedda y Nora, las ironías entre la señora X y la señora Y, llevan a los estudiantes a revisar su propia construcción como mujeres en el siglo XXI. Puso a circular los valores que pesan sobre la mujer, los tipos de acciones que se esperan o no de ellas. Al final de su intervención concluye:

Preguntas y cuestionamientos del que hacer dẹ lọs.lịcençịiặọs en artes escénicas:

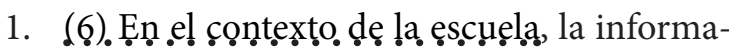
ción que debe circular con respecto

2. a la enseñanza del teatro parte de la pregunta: ¿pạara quéé? y ésța pẹrmịite

3. ențender que lạ Razọn dẹ.Ṣẹ. dẹl pedagogogo en esçéṇị̣as es brịndạle.

4. herramiẹntạsa a los alụmnọs para que puedan conocer y ampliar los

5. contenidos que hacen parte de un contexto cultural, y que además

6. rẹconozçạn y hạblẹn dẹșę su.propia reạlịdạd y expẹriẹnçiạ personali más que

7. hacer teatro en la escuela formar "actores"o ejecutar un montaje teatral, es

8. permitirle al alumno que identifique y dé nombre a los referentes comunes

9. que se presentan en las relaciones interpersonales y los conflictos que se

10. presentan dentro y fuera de la escuela; por ejemplo, la noción de mujer en

11. la escuela, mirada desde el teatro, brinda la oportunidad de crear nuevos

12. mundos donde afrontar y superar los conflictos y discriminaciones que en

13. este espacio se presentan ${ }^{13}$.

Ella misma toma el objeto y lo define desde distintos lugares (topos); toma referencias de dos contextos -la escuela y el teatro- para, desde cada uno, definir objetivos específicos. En la medida en que cambia el lugar, cambia el medio. Desde su configuración

13 Estudiante 5. I-2009. 
como actriz (línea 2) señala una pregunta y dos renglones más adelante la responde (líneas 3 a 6), y deja abierta la pregunta para puntualizar sobre la información viable de introducir en la escuela a partir de otra pregunta. La estudiante, en su papel de discernir diferencias entre un lugar y otro, compara el sentido de un saber en el escenario (línea 8 y9) y el sentido del mismo objeto hacia la educación en la escuela. La estudiante compara cómo el actor se prepara para tomar del texto elementos de ser actor, y cómo el pedagogo extiende el saber que le brinda una obra para dar herramientas de leer el mundo. En el momento de la reflexión, ella analiza la diferencia entre leer un mismo objeto, desde distintos roles. El medio cambia según la intención de uso. En las líneas 1, 3 y 4, la estudiante asume como lugar específico para pensar sobre qué hacer con los contenidos que ha definido de su lectura. En las líneas 8 y 9 se sitúa en su rol de pensar la escuela y define temas específicos propios de ella.

\section{A modo de conclusión: el espacio escénico pedagógico apenas levanta el telón}

En un principio, la intención de reconfigurar los dispositivos de aula en el área en cuestión, buscaban definir el sentido del medio de formación que, desde las prácticas sociales de referencia (las obras escritas, la teoría de teatro), llegaba rico en significados para los estudiantes orientados por la figura del actor, pero no parecía reconfigurarse hacia la escuela en significaciones pertinentes. Antes de la implementación de las prácticas, los estudiantes creaban resistencias ante los discursos escolares en sus intentos por comprender las opciones en proyectos escolares. Con la implementación de los dispositivos de alternancia entre la universidad y la escuela, los estudiantes (y los profesores) encuentran ahora un espacio concreto propicio para a) comenzar a construir el sentido en la escuela, del teatro y de las disciplinas que lo configuran, $\mathrm{y}$ b) estudiar las tensiones entre las prácticas socioculturales y los proyectos escolares.

El escenario del aula, tanto en la universidad como en la escuela, se presenta ahora como espacio de confrontación entre lo que se viene haciendo y lo que se debería hacer, en tanto se comprende, se construye y se significa el rol docente en artes escénicas.

Las resistencias ante las propuestas de proyectos conjuntos con escuelas han disminuido notablemente. El compromiso de los estudiantes desde sexto semestre con los grupos escolares, con los proyectos de aula y con los dispositivos de indagación conjunta, permite continuar en el ejercicio de extender las fronteras del aula universitaria desde la licenciatura para comprender su sentido en la escuela.

Pero no basta la disposición del estudiante. Se visualiza como necesaria la disposición también de los profesores, de la universidad y de la escuela para continuar en las exploraciones. Los estudiantes hacen también parte de la devolución cuando, desde sus reflexiones, instalan preguntan sobre los dispositivos que permitan comprender el sentido de las prácticas del arte como mediador de formación. La discusión sobre obras de teatro, historia y contextos definiendo los procesos de comprensión y reactualización de todo aquello que circula dentro de una obra de teatro y su campo en la escuela, deberá allanar la práctica pedagógica de los estudiantes e instalar las bases para la acción docente profesional en lo que los hitos del teatro aporta a los formadores. Pero la práctica pedagógica se inicia en el aula universitaria, en cada una de las áreas de formación; se puntualiza en las experiencias y confrontaciones en los espacios escolares y define los contenidos específicos y sus dimensiones a partir de las discusiones en clase, la experiencia en el aula universitaria, y deberá dimensionar, a la vez, los trabajos de entrenamiento y actuación como parte de los saberes específicos en la disciplina teatral. Poéticas como área de saber también es un espacio abierto a reactualizaciones. Las dimensiones que desde la investigación se intuyen como pertinentes, horadan poco a poco un programa cuyos contenidos parecían inamovibles, pero que por el contrario, y en función del perfil de los futuros docentes, deberá redefinirse moldeando opciones instrumentales hacia las didácticas y la escuela.Д] 


\section{Bibliografía}

Aguirre, I. (2005). Teorías y prácticas de la Educación Artística. España: Octaedro.

Aristóteles (1999). Poética. México: Ed. Porrúa.

Aslan, O. (2005). Lacteur au XXé siécle. Ethique et tecnique. Paris: l'Entretemps.

Bajtin, M. (2004). Fragmentos sobre el otro. México: Taurus.

Bentley, E. (1964). The life of drama. Buenos Aires: Ed. Paidós.

Berger, L. y Luckmann, T. (2005). La construcción social de la realidad. Madrid: Amorrotu editores.

Boileau, N. (1966). L’art poétique. En oeuvres complètes. Bibliothèque de la Pléiade. Editions Gallimard.

Brecht, B. (2004). El pequeño órganon. Escritos sobre teatro. Editorial Alba.

Brousseau, G. (1990). IREM, Université de Bordeaux, Francia. Versión castellana de Luis Puig.

Buysse, A. (2007). Le théatre: au-delà du jeu. Cahiers de la section des sciences de l'education (No.114). Universite de Geneva.

Chevallard, Y. (1991). La transposición didáctica. La pensée sauvage, editions.

D’Amico, S. (1954). Historia del teatro universal. Editorial Losada.

Efland, A. (2004). Arte y cognición. La integración de las artes en el currículum. Barcelona: Octaedro.

Engeström, Y., Engeström, R. y Kärkkäinen, M. (1995). Polycontextuality and boundary crossing in expert cognition: learning and problem solving in complex work activities. Learning and Instruction, Vol. 5, 319-336.

Grotowsky, J. (1991). Hacia un teatro pobre. Buenos Aires: Siglo XXI editores.

Hauser, A. (1988). Historia Social de la literatura y el arte. Barcelona: Ed. Labor.

Horacio (1805). Ars poética. Biblioteca Nacional, en facsímil. Original impr. Real, 1805, Madrid.

Page, C. (2006). Eduquer par le jeu dramatique. Issy-lesMoulineaux: ESF.

Rickenmann, R. (2006). La question de la réception culturelle dans les enseignements artistiques. MEI.

Schön, D. (1998). El profesional reflexivo. Barcelona: Paidós.

Sensevy, G., Schubauer-Leoni, M. y Mercier, A. (2007). Agir ensemble: Laction didactique conjointe du professeur et des élèves. Presses Universitaires de Rennes.

Ubersfeld, A. (1990). Semiótica del teatro. Ed. Cátedra.

Vygotski, L. (2000). Historia del desarrollo de las funciones psíquicas superiores. En L. Vygotski, Obras escogidas III. Problemas del desarrollo de la psique (pp. 11-340) (L. Kuper, traductor). Madrid: Visor (trabajo original publicado en 1931).

Vanhulle, S. (en imprenta). Formar docentes competentes en lecto-escritura. Portafolio, interacciones sociales $y$ escritura reflexiva. Bogotá: UPNB. 